\title{
Realizing person-centred care in residential care facilities for young adults with complex and chronic disabilities: the understanding, perception and beliefs of workers
}

\author{
Lauren Rissanen BPsy (Hons) ${ }^{a}$, Carolyn Ehrlich BHlthSc (Nursing) Grad Dip PHC MComm \\ PHC (Hons) PhD ${ }^{b}$, Elizabeth Kendall BA Dip Psych $\mathrm{PhD}^{\mathrm{c}}$ and Heidi Muenchberger BBehPsy \\ (Hons) MClin (Neuro) $\mathrm{PhD}^{\mathrm{d}}$
}

a Outreach Mental Health Worker, Youth and Wellbeing Program, Catholic Care, Watson, ACT \& Population and Social Health Research Program, Griffith Health Institute, Griffith University, Meadowbrook, Queensland, Australia

b Research Fellow, Population and Social Health Research Program, Griffith Health Institute, Griffith University, Meadowbrook, Queensland, Australia

c Professor \& Research Director, Population and Social Health Research Program, Griffith Health Institute, Griffith University, Meadowbrook, Queensland, Australia

d Associate Professor \& Senior Research Fellow, Population and Social Health Research Program, Griffith Health Institute, Griffith University, Meadowbrook, Queensland, Australia

\begin{abstract}
Young people living with complex and chronic disabilities who require assistance with health-related needs are rarely receiving the optimum support and care that will enable their full participation in society, or simply to live as they choose. For young people with complex disabling health conditions, this situation may not only be unpleasant, but may have a detrimental impact on their outcomes. In Australia, considerable attention has been paid to the relocation of people from institutional care into community settings within purpose-built apartments. However, it is the service model and the residential workers who articulate that service model into practice that are crucial to stimulate better outcomes for young people. In this study, a qualitative design was used to identify the major ways in which residential workers understood and articulated person-centred practice for young people with complex disabilities. Data were thematically analysed using an $a$ priori coding framework. The study identified 4 main themes relevant to person-centred practice in this setting, namely: 1) recognition of the person in time and context; 2) recognition of individuality; 3) recognition of the relationship and 4) promotion of autonomy. Importantly, the themes were connected in a broad and multi-level way through communication. The findings indicate that to enact behaviours congruent with person-centredness, residential care workers may need to reframe their professional role, image and values. However, several barriers hindered this process (i.e., system/organisational constraints, time etc.) and participants clearly needed support, education and/or mentoring to improve their capacity to apply person-centred models and also to create meaningful care partnerships.
\end{abstract}

\section{Keywords}

Beliefs, complex care needs, nursing, perceptions, person-centred care, residential care facilities, understanding, young adults

\section{Correspondence address}

Dr. Carolyn Ehrlich, LO5 1.14, Logan Campus, Griffith University, University Drive, Meadowbrook, Queensland, Australia, 4131. E-mail: c.ehrlich@griffith.edu.au

Accepted for publication: 26 February 2013

\section{Introduction}

Young people living with complex and chronic disabilities who require ongoing assistance with health-related needs rarely receive optimal support and care to enable their full participation in society or simply to live as they choose [1]. For the portion of this population who live in residential care settings (i.e., aged-care homes), care is predominately focused on medically-defined physical needs [2-6]. This current method of service delivery is endorsed through the dominant medical model paradigm, which attends to the physical cause of illness. Hence, residential aged-care facilities are equipped and designed for the maintenance of skills, management of deterioration and preparation for death, rather than the development of new skills, or the recovery of skills that have been lost [6,7]. Young people with complex and chronic healthcare needs require support and assistance to realise their individual goals, hopes and dreams and services need to respond by emphasising hope, enthusiasm and vibrancy [5]. However, workers within 
these settings are often unable to fully cater for the social and emotional needs of young people [2,5].

Service delivery models must attend to the broader spectrum of a young person's life, addressing the specific and multifaceted needs of this group [8-10]. Service models therefore need to provide opportunities for social engagement and involvement in recreational activities [5,6]; access to rehabilitation or therapy services $[4,11]$; psychological and emotional support and assistance to learn and manage tasks of daily living [12]. In Australia, considerable attention has been paid to the relocation of people from institutional care into community settings within purpose-built apartments. However, changing the physical environment alone is insufficient to improve quality of life and satisfaction for young people with complex disabling health conditions. Rather, service delivery models need to respond to the social and emotional, as well as to the physical needs of this population.

A person-centred approach to the delivery of care has been advocated as ideal for improving the lives of young people with complex disabling health conditions $[13,14]$. In the broader context, person-centredness has many positive practical benefits for those receiving ongoing care [15-20]. A person-centred approach requires care provision that holistically addresses the unique needs and concerns of individuals, whilst simultaneously promoting autonomy and personal responsibility [15]. The goals of personcentred care are to establish friendships, reduce social isolation and segregation and, broadly, to re-engage with the community in a manner that is consistent with the preference of the person [13]. Thus, practising in a personcentred manner means residential care workers will promote residents' autonomy and empowerment, individuality and participation in decision-making [10].

Although there is an emphasis and expectation that residential care workers will practise within a personcentred manner, there is no commonly agreed definition of 'person-centredness'. Person-centredness is complex, both in design and breadth and has been articulated in many different ways, with divergent definitions focusing upon different segments [8,21]. Williams and Grant [22] focused upon the subjective meaning and individualisation aspect of person-centredness, whereas McCormack [20] conceptualised person-centred as "authentic consciousness" of the residential care worker to stimulate the autonomy and decision-making of an individual. Further misunderstanding is generated by the differences in and lack of conceptual adherence of terminology for the concept of centredness and holistic care in general [9]. The lack of an agreed and inclusive definition creates confusion and uncertainty for workers, making person-centredness difficult to operationalise and enact in real-life contexts.

The implementation of a person-centred approach is complex not simple and has largely been misapplied in service systems [13,23]. The reasons for this misapplication are varied and include: misunderstandings of the process [23]; insufficient resources [24]; failure to integrate person-centred planning into the existing team culture and process [25] and professional unwillingness to relinquish power to the care recipient [26,27]. Moreover, the tools and techniques of person-centred practice can be used to manipulate care recipients into compliance with the service system [28].

Residential care workers spend the most amount of time with this population and are key determinators of whether or not an organisation will successfully implement a person-centred approach [29]. Hence, their understanding of person-centredness will be critical to how it is enacted. However, little is known about how residential care workers actually perceive person-centredness. Thus, more research is needed to explore residential care workers' understanding of the concept of person-centredness and its execution [30]. This study aims to gain an understanding of how residential care workers understand the principles of person-centredness in a residential setting for young people with complex disabling health conditions.

\section{Methods}

Ethical clearance was obtained from the University Human Research Ethics Committee. A total of 40 permanently employed residential care nurses from a single care setting, which provide continuous nursing care to young people with complex and chronic conditions in an Australian metropolitan city, were invited to participate in the study. The setting was purposively selected because the service delivery model of the organisation advocated personcentred care and aimed to facilitate young people living in ways similar to their peers in the wider community. The participant response rate was $40 \%(n=16)$ and comprised nursing assistants $(n=14)$, an endorsed enrolled nurse $(n=$ 1 ) and a registered nurse $(n=1)$. Most of the participants were female $(n=14 ; 87.5 \%)$ with two males $(n=2$; $12.5 \%$ ), which was reflective of the characteristics in the sample population and the sector.

Semi-structured face-to-face interviews using an interview guide, which explored how person-centred practice was understood and transacted in the current context, were conducted by 2 researchers. The interview guide consisted of the following key topics: person-centred practice; knowledge; understanding and transaction within the environment (i.e., "How would you describe personcentredness in your own words?”); the process of planning resident care and monitoring outcomes (i.e., "What are the barriers and constraints to the current process?”); the focus of services that are delivered (i.e., "What are the components of a care plan?”); the process of goal development with residents (i.e., "How do staff currently identify goals with the residents?”); the role of residents and family in the service (i.e., "What role do you see the resident having in goal setting?”) and staff training (i.e., "What competencies - skills, attitudes and knowledge - do you need to deliver services in this residential care setting?”).

Interviews were audio-taped and transcribed verbatim. Interviews were thematically analysed using the following 
Table 1 Coding framework based on the Ten Principles of Person-centredness (adapted from Hughes, Bamford \& May, 2008) [35]

\begin{tabular}{|c|c|}
\hline Theme & Description \\
\hline 1. Respect for individuality and values & The importance of valuing people as individuals. \\
\hline 2. Meaning & Accepting the unique and individual perspective which is grounded in personal experience. \\
\hline 3. Therapeutic alliance & Genuine empathy and unconditional positive regard based for the individual. \\
\hline 4. Social context and relationships & Recognition of the social nature of people, with an emphasis on relationships. \\
\hline 5. Inclusive model & $\begin{array}{l}\text { An integrated holistic understanding of the individual's unique world and life-setting that is } \\
\text { broader than diagnosis and treatment and includes promoting health, preventing disease and } \\
\text { improving quality of life. }\end{array}$ \\
\hline 6. Expert knowledge & $\begin{array}{l}\text { Individual's and their families have expert knowledge and experience that can contribute to the } \\
\text { development of professionals and service providers. }\end{array}$ \\
\hline 7. Shared responsibility & $\begin{array}{l}\text { Shared power, responsibility and control between service users and service providers. Mutual } \\
\text { agreement and shared decision-making. Collaborative partnerships with service users. }\end{array}$ \\
\hline 8. Communication & $\begin{array}{l}\text { Careful, sensitive, interactional dialogue, which fully uses observational skills and authentic } \\
\text { contact in affirming and useful ways. }\end{array}$ \\
\hline 9. Autonomy & $\begin{array}{l}\text { Decision-making processes that uphold the principles of self-determination and promote } \\
\text { independence and enhance individual control during the care process. }\end{array}$ \\
\hline 10. Professional as a person & Staff are valued and meaningful partnerships are supported. \\
\hline
\end{tabular}

steps [31-34]: (1) an a priori coding framework based on Hughes et al. [35] (refer Table 1) was applied manually across the whole dataset and used as a means of searching for, and retrieving chunks of, labelled data [36]; (2) all data were coded for barriers to adopting a person-centred approach; (3) data were separated into textual chunks and interpreted thematically; (4) $25 \%(n=4)$ of interviews were randomly selected and dual-coded by 2 independent coders to check the validity of interpretive claims [37] \& (5) categories were examined to identify relationships and associations within single interviews and across the entire dataset. Team members discussed emerging themes to determine their relevance and relationship [38] until the most important and stable categories were identified [33].

\section{Results}

After coding the data, it was apparent that the findings clustered into 4 distinct themes. These meta-themes were determined on the basis of co-occurrence of themes within interviews (i.e., represented by the same section of text, regularly appearing together in text, or explicitly linked together by the participant). The 4 themes were: 1) 'Recognition of the Person in Time and Context', which included the a priori codes 'inclusive model of health and wellbeing' and 'social context and relationships'; 2) 'Recognition of Individuality', which comprised the a priori codes of 'respect for individuality and values', 'meaning' and 'expert lay knowledge'; 3) 'Recognition of the Relationship', which included the a priori codes 'therapeutic alliance', 'shared responsibility' and 'professional as a person' and 4) 'Promotion of Autonomy', which reflected the a priori code of 'autonomy'. The themes were connected through 'Communication', but in a much broader and multi-level way than expected. Figure 1 outlines the interconnectedness between communication and the themes.

\section{Theme 1: Recognition of the person in time and context}

Participants operated predominately from a medical paradigm and there was little evidence of operating in accordance with a broader framework:

"These guys [residents] need physical help, these guys have got everything. These guys are unappreciative of what they've got and they forgot where they've come from [i.e., from nursing homes/hostels]...” (ID 16).

Rather than attending to the biopsychosocial needs of the whole person, physical care was the central focus and based on a day-to-day physical response, rather than being viewed as part of a continuous, flexible journey which supported residents to live a lifestyle of their choosing. On the whole, participants did not appreciate that residents might still have hopes and dreams, despite physical limitations. Only minimal reference was made to the residents' self-identified goals and, when mentioned, they were predominantly physical (i.e., to improve walking or mobility), rather than psychosocial.

A few participants expressed momentary insights into the biopsychosocial needs of residents, recognising that the purpose of the organisation was to provide a home environment, stimulating comfort, attachment, identity and inclusion:

"To be able to let young people live in a home environment, and be able to get them out in the community and do day-to-day things as much as possible that they would've done” (ID 11).

However, these statements were usually followed by reference to medical limitations and/or difficulties associated with supporting community and social activity. 
Figure 1 Interconnectedness between communication and a priori themes

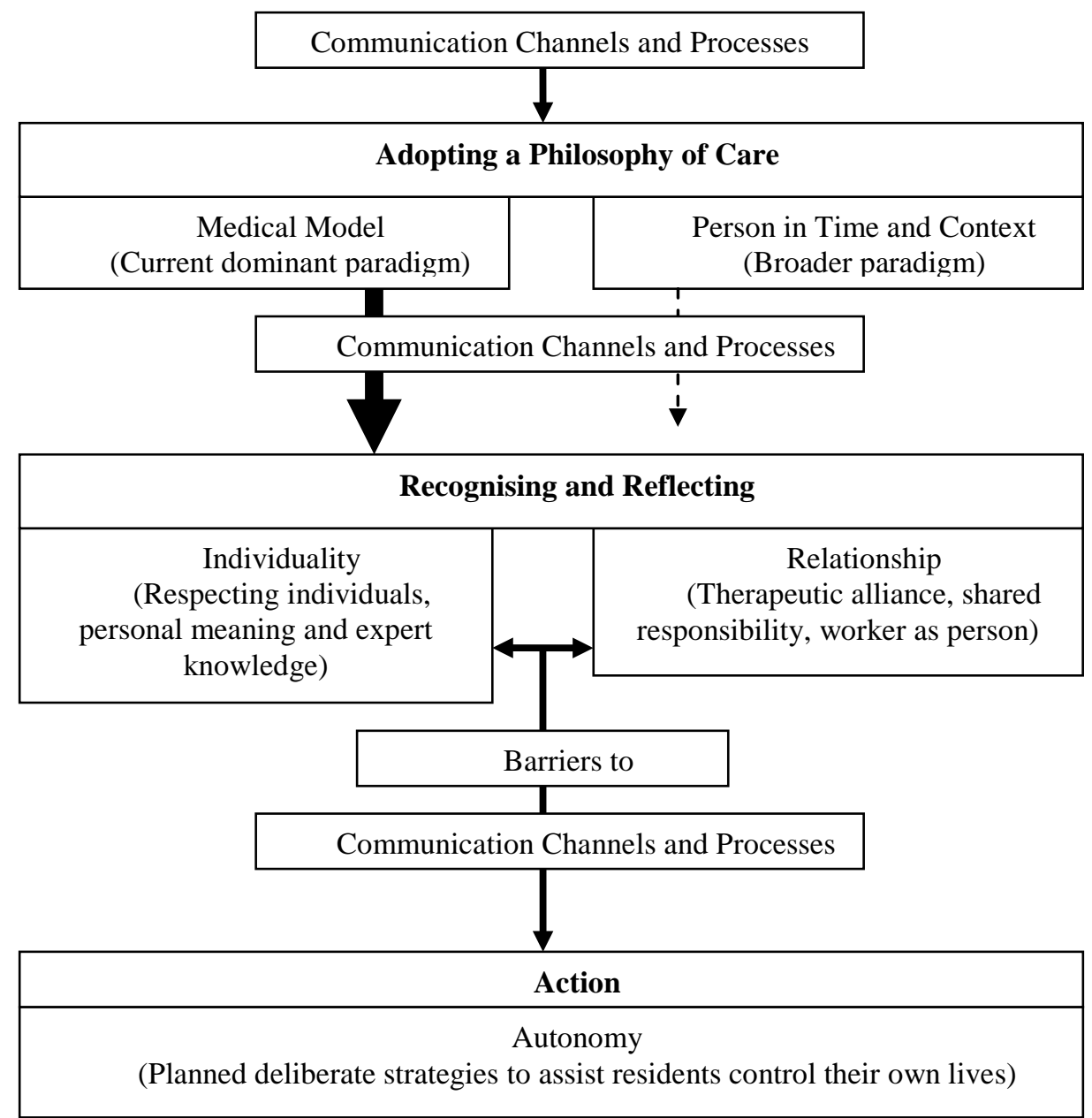

Little reference was made to psychological needs, other than brief displays of empathy for the difficult circumstances of residents. If mentioned, the social and emotional needs of residents were usually an afterthought, or were qualified and negated. The ability to attend to broader needs was constrained by time pressure. For example:

“...I think because they liked the companionship with that, I think they're actually - a lot of the residents, they often comment how lonely they are. Even though we're here all the time and they've constantly got people around them but they don't get that social aspect with them that we used to do [due to time constraints]. Now it's just the care work, do it, get out, next person, get out, next person” (ID 13).

The majority of participants were aware that emotional needs and challenges were important. However, there were mixed responses to such concerns. One participant stated that they were unwilling to broach these 'deeper' topics, preferring to:

"keep it light and happy for the sake of the residents" (ID 16).
Several participants reported their attempts to alleviate the emotional distress of residents by simply talking and listening, when time permitted:

"Some of them get quite depressed. I personally take that on board a bit because I think I'm supposed to try and alleviate that a bit" (ID 1).

However, most participants felt ill-equipped to deal with mental health issues, referring to such needs as the "job of a psychologist":

“...we are dealing with [named disabling condition], we're not dealing with psych[iatric] residents and the staff are not equipped with that. I'm not saying that we are not capable of that, we are not a psych[iatric] facility” (ID 9).

There was minimal recognition of residents as social beings embedded within a social group. Several participants commented about the need for residents to maintain contact with family, friends and the wider community. They recognised that friendships between residents were important and supported activities, such as residents making dinner together or engaging in social time with music. Some participants recognised the potential gains that might be derived from social engagement: 
“...I think because he's such a positive person, it makes you want to spend more time with them than you have. He's really, really benefitted from that” (ID 11).

Concrete examples of community inclusion were simplistic, such as shopping, or going to the movies. Several barriers were reported that hindered the facilitation of the residents' social needs, the most common of which were lack of time and resources. Unfortunately, many participants described how residents were becoming increasingly isolated and lonely, but were unable to describe strategies to address this challenge. They also described the increasing prevalence of challenging social behaviours among residents (e.g., violence, aggression, annoyance, non-compliance, withdrawal). Only one participant acknowledged that such behaviours could be a communicative expression of unmet social and emotional needs:

“Then she'll buzz [using a call bell system to obtain worker assistance] again, what time is it? She's got a clock right in front of her. It's just for the attention because she doesn't like to be left alone, but if you went in there and gave her half an hour, like the other night I went in there, no one was buzzing... To spend that half an hour in there with her was like the world to her" (ID 6).

Other than a few formal attempts to facilitate social activities, there was no overarching framework or strategy being used to address this area of need.

\section{Theme 2: Recognition of individuality}

'Individuality' was focused on respecting the residents as individuals, with differences in their likes and dislikes, acknowledging that their personal experiences were important and that they should not only be involved in care planning, but that they should ultimately be the final decision-makers about their care. All participants recognised residents as distinct individuals, with differences in preferences for personal care and that the experience of illness for each resident had a unique and idiosyncratic meaning. The way each resident thought about his or her circumstances was seen as being important to understand and that their right to an opinion must be respected by participants. Similarly, a resident's right and desire to be involved in care planning was valued. However, in articulating these beliefs and values, participants did so as part of a natural human response that might be expected from a caring individual, rather than as a strategic function of a person-centred philosophy. The presence of 'individuality' as a theme was arbitrary and evidenced through the articulation of ideas, rather than the description of actual care behaviours. Further, the notion of individuality was inconsistent and often contradicted:

"Everybody is affected differently so there are no two people with all the same symptoms" and then later on "I think most of the people [with a specific condition] are just resigned to this because it's not going to get better” (ID1).
Some participants referred to illness using collective references that overlooked individuality.

There appeared to be differing levels of understanding of 'individuality'. At the most basic level, there was superficial awareness of the need for an individualised model of care, but deeper insights and understanding were often not expressed:

"Because they're [residents] each individual... that's what we're based on - [our role] is to find out what they each need and then put it in their care plans” (ID 2).

When it was expressed, a deeper understanding of individuality was associated with resident wants or desires, based on some knowledge of the resident's broader life context:

"I think because these people here, although they can't speak or they can't talk, communicate properly, they're still young at heart, they still have needs that a normal woman and man wants, they still have desires” (ID 9).

The fulfilment of individual desires was acknowledged as important to improving quality of life, but was also acknowledged as a basic right to live life as he/she chooses. To a lesser extent, there was mention of the role of different personalities and that care had to reflect this.

It was noted that personal experience of illness affected individuals differently. However, this recognition was mostly expressed as a broad sweeping statement focused on the physical manifestation of disease rather than on how illness was subjectively experienced:

“...Everybody is affected differently as well so there are no two people with all the same symptoms so everybody is affected in a different way" (ID 1).

A number of participants expressed the need to know more about residents' diseases in order to effectively deal with challenging behaviours. It was assumed greater medical knowledge would enable them to manage the person, rather than acknowledging behaviour as a form of expression. However, a small number of participants were able to respond to the whole person and understand his/her behaviour from a personal perspective, putting challenging behaviour into context.

\section{Theme 3: Recognition of the relationship}

Participants generally described relationships in ways that reflected genuine interest, warmth and liking. A few participants explicitly described their relationships with residents as friendships. Importantly, relationships were perceived as being vital for the care partnership, positively impacting on care provision and facilitating residents to feel comfortable in requesting services:

"We've built all these friendships and relationships and I think that's what mostly it impacts on - we want to do it [provide care] well if we've got that relationship with them" (ID 4). 
Concrete examples of the alliance with residents involved engaging in conversations with residents during the provision of mundane physical care and through words of encouragement. Participants demonstrated an overarching human tendency to care for another person with whom one is in a relationship.

Despite the overwhelming sense of sympathy and compassion among participants, there was a lack of definitive and skilled strategies through which to build a therapeutic alliance. The alliance remained an ad hoc interaction characterised by pity, rather than one based on clarity about maximising benefits through the nature of the relationship. The most obvious gap was the dearth of unconditional positive regard (i.e., genuine acceptance). Participants appeared to have a "fair-weather" type of relationship with residents and although they experienced pity and sympathy for a resident's circumstances, any level of negativity expressed by residents exerted strain on the relationship, often resulting in harsh criticism from participants. Thus, the relationship was conditional upon the residents behaving as one would expect from a friend, rather than as a service-using person.

Being aware of and attempting to manage one's own feelings helped participants deal more effectively with conflict. They described deliberate strategies for working within delineated roles. A degree of separateness was considered beneficial by some participants (i.e., a warm interest, but without emotional over-involvement). Those who managed their feelings better were those who described a stronger understanding of the therapeutic alliance and the need for shared responsibility. When personal reactions were not managed well, the professional as a person dominated rather than guided practice, resulting in resentment and critique of residents at a personal level. Participants clearly required more support than they were receiving and a state of burnout and exhaustion was evident:

\begin{abstract}
"We probably also need someone to talk to ourselves ... just to talk things out on how we're feeling, because I know there's such a negative attitude here amongst staff, because they're just so drained and had enough and just can't cope any more. So little things that wouldn't normally bother you are these huge, massive things. So I think, you know, again, a professional person to come in and just to sort it all out and put us back into perspective" (ID 13).
\end{abstract}

Organisational barriers influenced the extent to which relationships could be translated into shared responsibility, rather than one-way care interactions. For instance, nursing assistants, who spent the majority of time with residents, did not have a direct role in the care planning process. Although able to provide input where necessary, there was disagreement about the exact extent:

\footnotetext{
"Because whatever we say, the clinical nurses are the ones planning everything and I think sometimes if it creates a little bit of conflict, they will be the one to update the care plans" (ID 15).
}

Shared responsibility was seen as a process of being observant and interacting with the resident by asking questions about how they wanted to work together with the workers.

The vital role of collaboration, negotiation and compromise in building a therapeutic relationship, or a relationship based on shared responsibility, was foreign to most participants. Participants demonstrated a lack of knowledge and of strategies about how to ensure residents' requests were facilitated, but within a framework of shared responsibility and a therapeutic context. They also lacked skills to manage challenging or demanding behaviour by residents without labelling the behaviour as being personally offensive. Hence, participants inadvertently facilitated situations that resulted in a reduced sense of responsibility by residents, an increased sense of responsibility by participants and a stressful nontherapeutic environment in which all parties felt undervalued. Thus, participants were unable to identify creative ways of managing difficult circumstances and maximising limited resources and services to best support the residents.

\section{Theme 4: Promotion of autonomy}

Most participants demonstrated a broad and vague understanding of autonomy, which was usually misinterpreted as:

\section{“... just centred around their [resident's] needs and what} they want” (ID1).

When probed, the majority of participants described a superficial form of autonomy, reflecting choice in terms of physical care only (e.g., when to shower, get up, when and what to eat). Ironically, when residents expressed their right to choose, participants commented that residents were too demanding and requested unnecessary assistance. The ability to identify and facilitate choice for residents was constrained by factors such as, lack of time, inadequate staff-to-resident ratio and limited financial or physical resources:

\footnotetext{
"I think the concept of [the facility] was just beautiful and the way it came about was just absolutely wonderful and this complex [physical building] and everything but [organisation founder] promised them everything, absolutely everything. To deliver everything that they expect we need to double our staff but we've had to haul our numbers in and we've had staff cutbacks. So their expectations are so high which brings me around to the fact that they are demanding” (ID 16).
}

To respond to demands on their time, participants tried to develop routines, which decreased the autonomy of residents:

\footnotetext{
"Like you know their routine inside out, you get them up every single day, but they have so much power over you. Like stop, now we're going to do it like this and they tell you the same thing every single day (ID 11).
} 
Some participants advocated for more routines in order to clarify expectations, and save time:

“...at least you can say if their care plan is out and you know exactly what's done it's easier for us and it's easier for them, because everything gets done to their satisfaction and it's got done quickly" (ID 13).

These practical views of autonomy were based on physical care needs, but overlooked the holistic needs of residents. Additionally, some resistance to autonomy was expressed:

"like I reckon it's insulting almost to the people - they know they're living in a facility. They're not stupid. They don't need to pretend" (ID 5).

Only one participant conceptualised autonomy thoroughly, expressing the role of staff as facilitators, to assist rather than dominate, in order to increase the residents' mobility and eventual independence. One participant noted that physical impairment should not equate to lack of independence and advocated for decisional autonomy and control by residents over everyday routines:”

"With the residents, yeah and I told them from the beginning, like I'm not here to do things for you, I really want you to think about the things that you want to do and I'm just here purely to try and be the engine to get that happening” (ID 1).

However, this participant described how difficult it was to put theory into practice as a result of the absence of a 2-way relationship and good communication with residents:

“but I haven't had a great deal of response... they [residents] just seem to be happy to sit back and just have things happening around them” (ID 1).

One participant described a simple yet illustrative example of how autonomy was not produced in the current setting. She described an interpersonal conflict with a resident based on the fact that the staff member had refused to perform an activity (i.e., reading a diary), which the resident was capable of doing independently once the staff member had facilitated the situation (i.e., by getting the diary, putting reading glasses on):

\footnotetext{
“Just think about it. You shouldn't even be asking me this. You should be encouraging yourself to do whatever you can do for yourself because if you don't, it's [physical functionality] not going to come back" (ID 8).
}

Thus, the data revealed how current practices appeared to be instilling a sense of dependency, reliance and overextension that was not commensurate with the level of disability among residents. This outcome was the antithesis of person-centredness and was based on a misinterpretation of autonomy by all parties.

In summary, the theme 'Recognition of the Person in Time and Context' represented a philosophy of care or a way of thinking about the person that, in turn, influenced the way in which care was conceptualised by participants. This theme involved a focus on the individual's life as a whole and comprising a broader social network, rather than being restricted to the immediate care environment. Participants who held this view described care as a continuous partnership over time, through which the individual's life stage and valuable role in the community was enabled. This view formed a framework from which participants guided their behaviour, thus enacting personcentred principles. However, even for those who held this view of care, the medical model was a competing paradigm that exerted considerable influence on their translation of that view into practice, thus resulting in behaviours that were counterproductive. There was clearly a need for a better understanding of and, orientation to, the person-centred model and how to translate theory into practice. Most participants discussed the need for education, training or mentoring to build their capacity to apply principles despite systemic barriers.

At the next level (Recognition of Individuality' and 'Recognition of the Relationship'), a constellation of the 'individuality' and 'relationship' themes was represented, indicating a way of reflecting on practice which could enhance or detract from person-centredness. 'Individuality' was focused on respecting residents as individuals foremost, with differences in their likes and dislikes, acknowledging that their personal experiences were important and that they should not only be involved in the care planning, but ultimately be the final decision-makers about their care. In contrast, the 'relationship' theme focused on the need for awareness of the interconnected and interdependent nature of the residential setting, involving a relationship between 2 people with a 2-way impact. The expression of these 2 themes should have been a natural consequence of the philosophy being adopted, but given the relative absence of that philosophy among participants, it is not surprising that these themes were presented in a non-therapeutic manner. Although a considerable amount of insight, genuine interest and care was evident, most participants appeared to be operating from an interpersonal and human stance, rather than from the point of a strategic, person-centred interaction. The articulation of these interpersonal reflections into personcentred practice was constrained by the presence of hierarchical structures and processes based on expertdriven systems and the lack of effective communication and resource/time constraints.

'Promotion of Autonomy' emerged as a clearly distinct theme and represented an outcome that was most likely to emerge as a result of all the preceding themes working in unison. When it was expressed, autonomy represented a deliberate strategy designed to assist or enable individuals to make their own independent decisions and to live life in a manner of their choosing. However, coinciding with an inadequate orientation to the 'Recognition of the Person in Time and Context' philosophy of care, it mostly represented a superficial form of autonomy.

Finally, although embedded within each theme, communication emerged as an independent process that 
either enabled the remaining themes to form a coherent approach to person-centredness, or acted as a barrier by its absence. Little in the way of communication between participants and residents was described. Instead, it seemed that both parties had come to rely on negative forms of communication such as silence, buzzing for attention, complaining and sarcasm. This finding suggests that attention was needed to support staff and residents to build person-centred relationships based on more than cycles of pity and resentment. Effective communication strategies were one way of building person-centred relationships. Communication was, therefore, an interconnecting or disconnecting theme that occurred at the levels of the organisation, staff to staff and resident to staff.

\section{Disc ussion}

This study has revealed an implicit assumption that, if articulated in the service delivery model of an organisation, the core principles of person-centredness will automatically form an integral component of practice among residential care workers. However, the findings have highlighted that an organisational commitment to a person-centred approach is insufficient, because significant barriers impede efforts to evolve practice in ways that encompass these valued dimensions. Consequently, it is easy for organisations and workers to adopt the rhetoric of person-centredness, rather than actually practising personcentred care [13,39-41]. Similar to the findings of other researchers, participants in this study predominantly oriented their practice and behaviour using the dominant medical paradigm [3,41-43]. Despite personal and organisational rhetoric about the social and emotional needs of residents, participants continued to focus on the day-to-day medical and physical needs, thus emphasising limitations and deficiencies.

This overwhelming pre-occupation with medical and physical care appeared to reflect a system in chaos, not adequately structured, resourced, or designed to achieve inclusion, autonomy and therapeutic alliances. As Holburn [13] demonstrated, systemic barriers can dissipate the best plans and efforts to change practice, resulting in a resumption of familiar methods of service delivery. The findings illustrate the importance of residential care workers' understanding of their scope of practice and job role, which directly shapes their enactment of personcentred principles. To enact behaviours congruent with person-centredness, residential care workers may have to reframe their professional role, image and values. However, participants clearly needed support, education and/or mentoring to improve their capacity to apply person-centred models and also to create meaningful care partnerships grounded in effective communication techniques.

Participants were largely unaware of their professional autonomy and did not realise the potential therapeutic power of the helping relationship. Dieppe, Rafferty and Kitson [44] stated unequivocally that the relationship between health professional and patient is the most important component for effective therapeutic change. Furthermore, Rogers [45] emphasised the importance of the relationship and being able to freely experience positive feelings, a caring demeanour and a desire to understand, which the majority of participants possessed. However, participants required further support to effectively interpret and manage negative behaviours or expressed feelings of residents. In the absence of strategies, it was likely that the relationship would become conditional. A standard human relationship implies a lack of separateness from the other person, whereas a therapeutic alliance needs to be accepting, warm and honest, whilst maintaining a clear distinction between individuals. Once this different approach to a relationship is achieved, residential care workers can explore the personal world of residents through non-judgmental empathy, without fear of being engulfed by negative sentiments [45].

The most obvious gap to enacting person-centred care was the inability to provide autonomy-supportive practices. The predominant simplistic conceptualisation of autonomy resulted in undesirable behaviours and tensions that were counterproductive to the endorsed ideal. Simply respecting individuality and individualised care does not equate to promoting the autonomy of the individual in care [20]. Ironically, the lack of autonomy was experienced by both parties, with participants being equally hindered. Although both residents' and workers' values were important in the care partnership, they needed to remain separate, so that workers did not unduly influence the autonomous decisions of residents [9,21]. Hence, workers must be aware of their values, beliefs, desires and feelings and develop an awareness of how their behaviour can impact upon others.

The care planning process did not inherently express person-centredness. Ideally, care plans for residents should be updated to include all aspects of the individual's life; a life plan, rather than a medical care plan. A life plan would include all of the activities/goals the person wants to pursue, or a value the person wants to advance, as well as psychological and social information. Integrating life plan assessment into care planning enables the residents' social world to remain central to negotiated decision-making and communicates to workers the expected standard of practice. In contrast to this ideal situation, the current care planning format emphasized medical care, was the responsibility of 1 or 2 more senior staff and overlooked all other aspects of residents' lives.

In terms of recommendations for practice, there is a clear need for professional development, mentoring, education and training for workers. Mentoring, or professional/personal development, is crucial, so that workers can explore the values, beliefs and assumptions underlying their practice. As Rogers [45] asserted, it is the attitudes, beliefs and feelings of the therapist, rather than his or her theoretical orientation, that will determine successful adoption of person-centred practice. As emotions have an important role in the decision-making process for person-centred care [20], it is imperative that workers are effectively able to manage their emotional reactions. The strategy "reflection-on-action" [46] might 
be useful to aid residential workers in consciously exploring their practices. Reflection-on-action is a technique that involves reflecting upon one's practice whilst engaging in that behaviour in order to stimulate conscious awareness of one's motives.

A further implication of this study is that if nurses are to continue to provide residential care for this population, the nursing curriculum may need to include greater emphasis on the importance of care partnerships, choice and advocacy. Also, 'on-the-job' training to build skills and allow for practice is needed for workers. By incorporating a practical component, workers can become competent and explore effective techniques for enacting person-centredness.

This study was based on a small sample size, using convenience sampling. The sample was predominantly female and employed day-staff residential care workers who were nursing assistants. Wellard et al. [41] found different manifestations and understanding of personcentred practices across different levels of nurses within acute care contexts, highlighting the importance of further research. Finally, it is important to acknowledge that the study focused on experiences and understandings of residential care workers, rather than their actual behaviour. Despite these limitations, the study has provided a useful conceptualization of person-centredness that may be useful in improving the quality of residential care facilities. Nursing assistants provide the majority of direct care interactions with residents in residential care facilities. Thus, if person-centred care is to be enacted, these workers are fundamental to successful adoption of person-centred practices and need to be supported. Given that so many young people with disabilities are living in inappropriate settings $[1,2,6]$, the ability of our health workforce to create appropriate care environments will determine how successfully this challenge is addressed.

\section{Conclusion}

This study explored the nature of person-centred practice in the context of providing care for young people with complex and chronic health conditions. Theoretically, the study has explored and substantiated the core concepts of person-centredness contained in the current literature. A coding framework based on theory [35] was applied to a real-world context and was found to be meaningful and practically significant. However, the findings have also revealed 3 important areas relating to the complexity of person-centred practice. First, a fundamental component of person-centred practice for residential care workers is the availability of a comprehensive philosophy of care that orientates them to think about people in broader social, time and life contexts, encompassing entire individuals and the complexity of their lives. Second, it is important for residential care workers to be able to appreciate the individual resident, the relationship that exists between them and to reflect on the expectations that are implicit within that relationship. Third, workers need to be able to address barriers in their environments to enable the application of deliberate strategies that translate the philosophy and reflections associated with personcentredness into practice. Thus, the findings stress the need for a mixture of 'a way of being' and thinking (i.e., philosophy of care and reflective practice) and deliberate strategies to enhance the realisation of person-centred principles (e.g., autonomy or therapeutic alliances). To avoid person-centredness remaining at the level of rhetoric, it is clear from this study that understanding, which implies a continual process of learning and reflecting, must precede the techniques, which are the means to an end objective. Further, techniques are rendered powerless without adequate attention to systemic communication blockages, constraints and barriers that prevent action.

The current findings have revealed that organisations must communicate to staff the critical elements and philosophies of any new service model and then collectively discuss, elaborate and clarify how these elements can be translated into practice. Ideally, these new ways of thinking and behaving will become embedded in the attitudes of residential care workers and alter their ways of perceiving the provision of care. The findings have also shown that it is important to simultaneously facilitate change at both the personal and organisation level. Further, it is important to stimulate relationshipbuilding between co-workers at all levels of the organisation, providing a vehicle for expression and consideration of different perspectives and increasing conscious awareness of ways to practice in a personcentred manner [42]. Systemic processes (such as communication strategies, assessment and planning procedures, hierarchical expert-based care processes) must be analysed in terms of their ability to promote personcentredness.

\section{Conflcits of Interest}

The authors declare no conflicts of interest.

\section{References}

[1] Gilmore, V. (2002). Aged care is not the right place for younger people. Australian Nursing Journal 10 (1) 15.

[2] Cameron, C., Pirozzo, S. \& Tooth, L. (2001). Longterm care of people below age 65 with severe acquired brain injury: appropriateness of aged care facilities. Australian and New Zealand Journal of Public Health 25 (3) 261-264.

[3] Condeluci, A. (1992). Brain injury rehabilitation: the need to bridge paradigms. Brain Injury 6 (6) 543-551.

[4] O’Reilly, K. \& Pryor, J. (2002). Young people with brain injury in nursing homes: not the best option! Australian Health Review 25 (3) 46-51.

[5] Smith, M. (2004). Under the circumstances: The experiences of younger people living in residential aged care facilities. Contemporary Nurse 16 (3) 187-194. 
[6] Winkler, D., Farnworth, L. \& Sloan, S. (2006). People under 60 living in aged care facilities in Victoria. Australian Health Review 30 (1) 100-108.

[7] Disability Services Queensland. (2006). Younger People in Residential Aged Care Initiative. Service Specifications. Integrated Living Model, 1-17.

[8] Cott, C.A. (2004). Client-centred rehabilitation: client perspectives. Disability and Rehabilitation 26 (24) 14111422.

[9] McCormack, B. \& McCance, T.V. (2006). Development of a framework for person-centred nursing. Journal of Advanced Nursing 56 (5) 472-479.

[10] Schoot, T., Proot, I., Legius, M., ter Meulen, R. \& de Witte, L. (2006). Client-centered home care: Balancing between competing responsibilities. Clinical Nursing Research 15 (4) 231-254.

[11] Wales, L.R., \& Bernhardt, J.A. (2000). A case for slow to recover rehabilitation services following severe acquired brain injury. Australian Journal of Physiotherapy 46 (2) 143-146.

[12] Strettles, B., Bush, M., Simpson, G. \& Gillet, L. (2005). Accommodation in NSW for adults with high care needs after Traumatic Brain Injury. Sydney, Australia: Motor Accident Authority.

[13] Holburn, S. (2002). How science can evaluate and enhance person-centered planning. Research \& Practice for Persons with Severe Disabilities 27 (4) 250-260.

[14] Holburn, S. \& Vietze, P. (2002). A better life for Hal: Five years of person-centered planning and applied behaviour analysis. In: Person centered planning: Research, practice, and future directions (Holburn, S. \& Vietze, P.M., eds.), pp. 291-314. Baltimore: Paul H. Brookes.

[15] Brooker, D. (2004). What is person-centred care in dementia? Reviews in Clinical Gerontology 13 (3) 215222.

[16] Eales, K., Keating, N. \& Dasma, A. (2001). Seniors' experiences of client-centred residential care. Ageing and Society 21 (3) 279-296.

[17] Kitwood, T. (1997). Dementia reconsidered: The person comes first. Buckingham: Open University Press.

[18] Kitwood, T. \& Bredin. K. (1992). Towards a theory of dementia care: Personhood and well-being. Ageing and Society 12 (3) 269-287.

[19] McCormack, B. (2001). Negotiating Partnerships with Older people: a Person-centred Approach. Aldershot: Ashgate Press.

[20] McCormack, B. (2003). A conceptual framework for person-centred practice with older people. International Journal of Nursing Practice 9 (3) 202-209.

[21] Mead, N. \& Bower, P. (2000). Patient-centredness: a conceptual framework and review of the empirical literature. Social Science \& Medicine 51 (7) 1087-1110.

[22] Williams B. \& Grant, G. (1998). Defining 'peoplecentredness': making the implicit explicit. Health and Social Care in the Community 6 (2) 84-94.

[23] Lyle O'Brien, C., O'Brien, J. \& Mount, B. (1997).

Person-centered planning has arrived... or has it?. Mental Retardation 35 (6) 480-484.

[24] Mount, B. (1994). Benefits and limitations of personal futures planning. In: Creating individual supports for people with developmental disabilities: A mandate for change at many levels. (Bradley, V.J., Ashbaugh, J.W \& Blaney, B.C., eds.), pp. 97-108. Baltimore: Paul H. Brookes.

[25] Sanderson, H. (2002). A plan is not enough: Exploring the development of person-centered teams. In: Person-centered planning: Research, practice, and future directions. (Holburn, S. \& Vietze, P., eds.), pp. 97-126. Baltimore: Paul H. Brookes.

[26] Marrone, J., Hoff, D. \& Helm, D.T. (1997). Personcentered planning for the millennium: We're old enough to remember when PCP was just a drug. Journal of Vocational Rehabilitation 8, 285-297.

[27] Sumsion T. (1999). Client-centred practice in occupational therapy. A guide to implementation. Edinburgh: Churchill Livingstone.

[28] Ritchie, P. (2002). A turn for the better. In: Implementing person-centered planning: Voices of experience, 2nd edn. (O’Brien, J. \& Lyle O’Brien, C., eds.). Toronto, Canada: Inclusion Press.

[29] Miller, S. (1986). Relationships in long-term care facilities. Generations 70, 65-68.

[30] Jewel, S.E. (1994). Patient participation: what does it mean to nurses? Journal of Advanced Nursing 19 (3) 433438.

[31] Braun, V. \& Clarke, V. (2006). Using thematic analysis in psychology. Qualitative Research in Psychology 3 (2) 77-101.

[32] Dempsey, P. \& Dempsey, A. (1996). Nursing research text and workbook. Boston: Little, Brown.

[33] DeSantis, L. \& Ugarriza, D.N. (2000). The Concept of Theme as Used in Qualitative Nursing Research. Western Journal of Nursing Research 22 (3) 351-372.

[34] Morse, J.M. \& Field, P.A. (1995). Qualitative research methods for health professionals. Thousand Oaks, CA: Sage.

[35] Hughes, J.C., Bamford, C. \& May, C. (2008). Types of centredness in health care: Themes and concepts. Medicine, Health Care and Philosophy 11 (4) 455-463.

[36] Spencer, L., Ritchie, J. \& O’Connor, W. (2003). Analysis: Practices, principles and processes. In: Qualitative Research Practice A Guide for Social Science Students and Researchers. (Ritchie, J. \& Lewis, J., eds.), pp. 199-218. London: Sage Publications.

[37] Lewis, J. \& Ritchie, J. (2003). Generalising from Qualitative Research. In: Qualitative Research Practice A Guide for Social Science Students and Researchers. (Lewis, J. \& Ritchie, J., eds.), pp. 263-286. London: Sage Publications.

[38] Ryan, G.W. \& Bernard, H.R. (2003). Techniques to identify themes. Field Methods 15 (1) 85-109.

[39] Holburn, C.S. \& Vietze, P. (1999). Acknowledging barriers in adopting person-centered planning. Mental Retardation 37 (2) 117-124.

[40] Smull, M.W. \& Lakin, K.C. (2002). Public policy and Person centered planning. In: Person-centered planning: Research, practice, and future directions. (Holburn, S. Vietze, P.M., eds.), pp. 379-397. Baltimore: Paul H. Brookes.

[41] Wellard, S., Lillibridge, J., Beanland, C. \& Lewis, M. (2003). Consumer participation in acute care settings: An 
Australian experience. International Journal of Nursing Practice 9 (4) 255-260.

[42] Brown, D., McWilliam, C. \& Ward-Griffin, C. (2006). Client-centred empowering partnering in nursing. Journal of Advanced Nursing 53 (2) 160-168.

[43] McWilliam, C., Ward-Griffin, C., Sweetland, D., Sutherland, C. \& O’Halloran, L. (2001). The experience of empowerment in in-home services delivery. Home Health Services Quarterly 20 (4) 49-71.

[44] Dieppe P., Rafferty A.M. \& Kitson A. (2002). The clinical encounter - the focal point of patient-centred care. Health Expectations 5 (4) 279-281.

[45] Rogers, C.R. (1967). On becoming a person a therapist's view of psychotherapy. London: Constable.

[46] Schon, D.A. (1987). Educating the reflective practitioner: Toward a new design for teaching and learning in the professions. San Francisco, CA: Jossey Bass. 